\title{
STOOL FORM SCALE AS AN INDICATOR OF KLUTUK BANANA (MUSA BALBISIANA COLLA) FRUIT EXTRACTS INHIBITION EFFECT AGAINST SHIGELLA DYSENTERIAE ATCC 13313 IN VIVO
}

\author{
SRI AGUNG FITRI KUSUMA ${ }^{1 *}$, PUSPAGITA WARDHANI ${ }^{1}$, ELLIN FEBRINA ${ }^{2}$
}

${ }^{1}$ Department of Biology Pharmacy, Faculty of Pharmacy, Padjadjaran University, Sumedang, West Java, 45363, Indonesia. ${ }^{2}$ Department of Pharmacology, Faculty of Pharmacy, Padjadjaran University, Sumedang, West Java, 45363, Indonesia. Email: s.a.f.kusuma@unpad.ac.id

Received: 25 July 2017, Revised and Accepted: 06 September 2017

\section{ABSTRACT}

Objective: Stools consistency is a common symptom indicating in dysenteriae. The aim of this study was to investigate the inhibitory effect of the klutuk banana fruit extract that determine different degrees of stool consistency in dysentery induced by Shigella dysenteriae ATCC 13313 .

Methods: The extraction of klutuk banana fruits was prepared using a maceration method. The antidysenteriae activity of the klutuk banana extract was evaluated in vivo. The specific pathogen-free mice were intraperitoneally injected with $S$. dysentriae suspension cell. Observations were made for 7 days on body weight of mice, total fecal weight every $24 \mathrm{hrs}$ and consistency of stool. The level of stool consistency was measured based on Bristol Stool Chart.

Results: The results indicated that the body weight of each group was decreased the day after induction and the stool consistency was at level 5-6. However, both test groups could achieve the ideal type of stool (type 4) in the same period of time as a group with ciprofloxacin treatment.

Conclusion: It can be concluded that the ethanol extract of klutuk banana fruits is highly potent as natural antidysenteriae against $S$. dysenteriae.

Keywords: Klutuk, Banana, Shigella dysenteriae, Stool, Consistency.

(C) 2017 The Authors. Published by Innovare Academic Sciences Pvt Ltd. This is an open access article under the CC BY license (http://creativecommons. org/licenses/by/4. 0/) DOI: http://dx.doi.org/10.22159/ajpcr.2017.v10i12.21592

\section{INTRODUCTION}

Enteric pathogens of public health concern cause both diarrheal disease and fever of unknown origin [1]. Infectious diseases kill about 11 million children each year, while acute diarrheal diseases account for 3.1 million deaths in children under 5 year of age, of which $6,00,000$ deaths annually are contributed by shigellosis alone [2]. Shigellosis, also known as acute bacillary dysentery, is characterized by the passage of loose stools mixed with blood and mucus and accompanied by fever, abdominal cramps, and tenesmus [3]. Patients may, however, present only with acute watery diarrhea without visible blood or mucus [4]. In Indonesia, 29\% cases of diarrhea caused by bacillary dysentery and generally occur at age 1-4 years [5].

All cases of bloody diarrhea should be treated promptly with an antimicrobial that is known to be effective against Shigella. This lessens the risk of serious complications and death, shortens the duration of symptoms, and hastens the elimination of Shigella from the stool [5]. Antibiotics are the mainstay of therapy in all cases of shigellosis [3]. Originally, both sulfonamides and tetracycline were effective, but Shigella strains rapidly developed resistance to these agents. Ampicillin and trimethoprim-sulfamethoxazole were then used and continue to be effective in many industrialized countries. Unfortunately, in many parts of the world strains of all species of Shigella have become resistant to these low-cost agents, and neither can now be confidently used as empiric therapy for shigellosis [6]. Newer fluoroquinolones, such as norfloxacin and ciprofloxacin are still effective for shigellosis infection, but their price is very expensive. Therefore, we need another antibiotic candidate that effective and can be obtained at cheaper prices. This can be achieved by optimizing the plants that can empirically treat dysentery. Klutuk banana fruit has been proven empirically and also through in vitro research, can inhibit the growth of Shigella dysenteriae ATCC 13313 bacteria. The chemical components of the ethanol extract of banana contain flavonoids, polyphenols, tannins, monoterpenoid and sesquiterpenoids, quinones, and saponins [7]. Those secondary metabolites have been reported can act as an antibacterial agent.
Besides examination of fecal leukocytes [6] and Shigella colony number, stool consistency is very important to determine the effectiveness of shigellosis treatment. Because stools consistency is a common symptom indicating in dysentery. Based on the Bristol stool chart, the ideal stools are types 3 and 4, especially type 4, as they are most likely to glide out without any fuss. Therefore, the purpose of this study was to investigate the inhibitory effect of the klutuk banana fruits extract that determine different degrees of stool consistency in dysentery induced by S. dysenteriae ATCC 13313 in vivo.

\section{MATERIALS AND METHODS}

\section{Materials}

The chemical used are distilled water, ciprofloxacin, Mueller-Hinton Broth (MHB-Oxoid), Mueller-Hinton Agar (MHA-Oxoid), ethanol, and carboxymethylcellulose. The animal used in this research was male Mus musculus mice and the bacteria used were S. dysenteriae ATCC 13313. The ethical approval number of this research was no. 38/UN6.C1.3.2/ kepk/PN/2015 with no. Reg.: 0215050401.

\section{Plant material}

The samples that used in this study are Musa balbisiana colla fruits of Manoko Garden, Lembang, West Java, Indonesia. Plant sample was identified in Plant Taxonomy Laboratory of Biology Major, Faculty of Mathematics and Natural Science Padjadjaran University.

\section{Methods}

Preparation of fruits extracts

Dried simplisia of banana klutuk fruits were extracted using maceration method. Dried simplisia extracted by maceration during $3 \times 24 \mathrm{hrs} \mathrm{using}$ ethanol $70 \%$ as the solvent. The extracts were evaporated using a rotary evaporator at $40-50^{\circ} \mathrm{C}$, then continued to evaporate on a water bath until dried extract with a constant weight was obtained [7]

\section{Preparation of the bacterial suspension}

S. dysenteriae ATCC 13313 in $5 \mathrm{~mL}$ Shigella-Salmonella agar in the test tube was incubated for $18-24 \mathrm{hrs}$ at $37^{\circ} \mathrm{C}$. S. dysenteriae bacteria that 
have been cultured then suspended into a sterile physiological $\mathrm{NaCl}$ until the turbidity is equal to McFarland 4 [8].

\section{Antibacterial activity test in vivo}

After all the mice were adapted, initial identification of the feces of each mouse was performed. The identification includes weight, consistency of feces, and sterility of mice from $S$. dysenteriae bacteria. This initial identification was aimed to ensure that mice are healthy and not exposed to dysentery. After all, healthy mice were determined, the mice were divided into five groups: Normal, negative control, positive control, group 1, and group 2. All groups of mice except normal group were induced to be dysentery by administration of $1 \mathrm{~mL}$ of $S$. dysenteriae bacterial suspension with turbidity equivalent to McFarland 4 intraperitoneally. After diarrhea, group 1 and group 2 were given banana klutuk fruits extract suspension with $125 \mathrm{mg} / 20 \mathrm{~g}$ BW and $150 \mathrm{mg} / 20 \mathrm{~g} \mathrm{BW}$ orally twice in daily per day at 6:00 and 18:00. Positive control was given $20 \mathrm{mg} / \mathrm{kg}$ BW orally of antibiotics ciprofloxacin twice in daily. Type of preparation used in the study was suspended. The suspension was made by adding $1 \%$ carboxymethyl cellulose (CMC) to each of ciprofloxacin and banana extract of ethanol. The negative control group was given orally of 1\% CMC suspension. Normal control groups are fed without dysentery induction to ensure that the food given to the mice does not cause dysentery. This treatment was performed for 7 days after induction [9]. The observation of the consistency of the feces was done based on Bristol Stool Chart. For 7 days after induction, observation of body weight of mice, consistency of stool and total fecal weight every $24 \mathrm{hrs}$.

\section{RESULTS AND DISCUSSION}

\section{Yield of the extract}

The quality of viscous extract can be seen from the parameters, that is, through organoleptic examination, rendement test, and water content extract. Extract of banana klutuk ethanol (M. balbisiana colla) produced a number of $117.43 \mathrm{~g}$ with the characteristics are solid, distinctively, and brownish. From the result of calculation, got rendement of banana extract of banana yield equal to $7.339 \%$. The value of rendement relates to the quantity of secondary metabolites that were successfully attracted during the extraction process by comparing the weight of the viscous extract with the weight of the simplicia.

\section{Antidysenteriae activity result}

During the treatment, physical observation, body weight, total fecal weight per $24 \mathrm{hr}$, and the fecal consistency of the test animals were performed. Normal mice receiving only the food did not exhibit any diarrhea sign. Animals given test extracts and antibiotics looked more active and more mobile than negative control group. The negative control group test animals did not show much motor activity. The body weight of each group induced by dysentery averaged a decline the day after induction. This is because the emergence of clinical symptoms of dysentery, that is, diarrhea with a consistency that is quite fluid and slimy. In the condition of diarrhea, excessive discharge of body that can lead to dehydration and weight loss. However, from the results of observation, it was found that the body weight of the test animals began to increase after the consistency of the feces back to normal. The result of body weight observation from each group of animal test can be seen in Table 1.
The total fecal weight per $24 \mathrm{hrs}$ was observed to compare the normal stool weight of the control group with other dysentery-induced groups. From the data obtained, it was found that the total fecal weight of the denture-induced animal test group increased after induction compared with the total stool weight before induced. It shows that true dentistryinduced animals have increased frequency of defecation. This effect resulted because of the Shigella toxin occurs with rapid destruction of microorganisms in vivo could lead to endotoxin shock, which could result in high feces frequency [10]. The mean total weight of the feces of each animal group during the treatment can be seen in Table 2.

The consistency of feces of the test animals in the negative control group, the positive control group, the test group 1 and the 2-after $24 \mathrm{hrs}$ test induced by Shigella dysentriae bacteria were more flabby and liquid than normal control group. Observation of fecal consistency from each animal group test was conducted based on Bristol Stool Chart. The result of observation of consistency of feces can be seen in Table 3.

From the observations made, the fecal consistency of the induced animal test group began to decline 24 hrs after induction, with consistency of type 5 and type 6 of the Bristol Stool Chart where the feces tend to be soft, watery, and slimy. In the negative control group, the consistency of average feces still showed consistency of type 6 through day 3 of treatment. This is because a 1\% CMC suspension does not have any therapeutic effect on dysentery treatment. The consistency of the feces begins to show normal consistency (type 3) on the $7^{\text {th }}$ day of treatment. For the positive control group, the consistency of the feces showed the consistency of type 5 through day 3 of treatment and the consistency of normal feces could be observed on the $5^{\text {th }}$ day of treatment. This suggests that ciprofloxacin antibiotics have an erratic effect on S. dysenteriae bacteria. For test group 1 showing consistency of type 6 to day 2 treatment and normal fecal consistency can be observed on the $6^{\text {th }}$ day of treatment. The result of observation of the test group 2 has similarities with the positive control group, where consistency of type 5 can be observed until the $3^{\text {rd }}$ day of treatment and normal consistency can be observed on the $5^{\text {th }}$ day of treatment. The extract at the doses of $125 \mathrm{mg}$ and $150 \mathrm{mg} / 20 \mathrm{~g} \mathrm{BW}$, as well as the well-known drug ciprofloxacin, markedly repaired the diarrheic stool consistency by the $4^{\text {th }}$ day after induced. From these results can show that the extract of banana klutuk ethanol has the therapeutic effect of dysentery disease.

The results of the phytochemical analysis revealed varying constituents of these extracts, as follows: Flavonoids, polyphenols, tannins, monoterpenoids, sesquiterpenoids, quinones, and saponins [7]. Those phytochemical results assessment revealed the presence of phenols, saponins, flavonoids, and tannins, which possess antioxidant and antiinflammatory activities. As reported in another study, the methanolic extract of Tabernaemontana divaricate stem gave the antibacterial activity against $S$. dysenteriae due to the same contents of secondary metabolites as the banana klutuk fruits extract [11]. These activity were in line with another research which reported that the banana fruits extract content higher total phenolic compounds than its skin [12]. Flavonoids are responsible for the inhibition of intestinal motility and secretion, which could lead to a decrease in the frequency of wet feces [13]. The antimicrobial properties of anthraquinones, saponins, and phenols may prevent the infections. Flavonoids also could inhibit inducible nitric oxide synthase, which lead to the reduction

Table 1: The average of mice weight

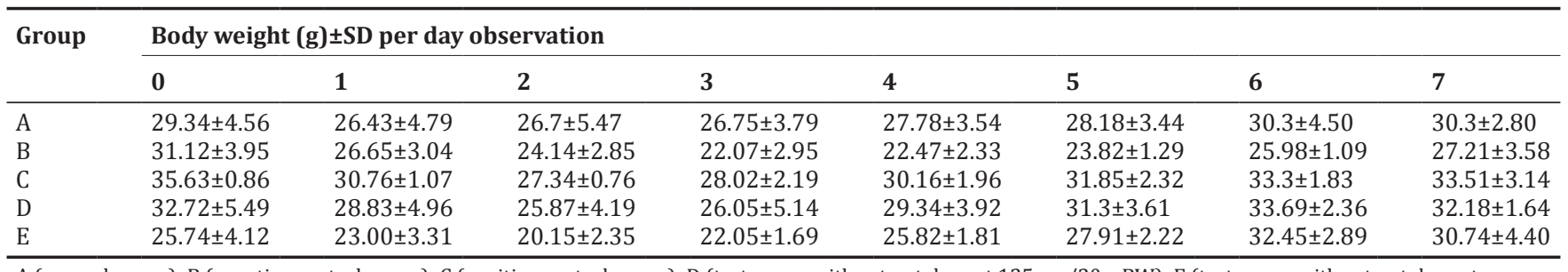

A (normal group); B (negative control group); C (positive control group); D (test group with extract dose at $125 \mathrm{mg} / 20 \mathrm{~g} \mathrm{BW);} \mathrm{E} \mathrm{(test} \mathrm{group} \mathrm{with} \mathrm{extract} \mathrm{dose} \mathrm{at}$

$150 \mathrm{mg} / 20 \mathrm{~g} \mathrm{BW})$. SD: Standard deviation 
Table 2: Total feces weight (g)

\begin{tabular}{lllllllll}
\hline Group & \multicolumn{6}{l}{ Total feces weight $(\mathbf{g})$ per day of observation } \\
\cline { 2 - 9 } & $\mathbf{0}$ & $\mathbf{1}$ & $\mathbf{2}$ & $\mathbf{3}$ & $\mathbf{4}$ & $\mathbf{5}$ & $\mathbf{6}$ & $\mathbf{7}$ \\
\hline A & $0.338 \pm 0.05$ & $0.316 \pm 0.09$ & $0.384 \pm 0.06$ & $0.346 \pm 0.05$ & $0.382 \pm 0.04$ & $0.324 \pm 0.04$ & $0.318 \pm 0.08$ & $0.328 \pm 0.06$ \\
B & $0.326 \pm 0.05$ & $0.552 \pm 0.11$ & $0.588 \pm 0.07$ & $0.566 \pm 0.07$ & $0.484 \pm 0.03$ & $0.390 \pm 0.04$ & $0.354 \pm 0.07$ & $0.308 \pm 0.06$ \\
C & $0.362 \pm 0.05$ & $0.532 \pm 0.07$ & $0.442 \pm 0.08$ & $0.402 \pm 0.08$ & $0.378 \pm 0.04$ & $0.346 \pm 0.04$ & $0.308 \pm 0.04$ & $0.256 \pm 0.08$ \\
D & $0.364 \pm 0.09$ & $0.596 \pm 0.12$ & $0.588 \pm 0.05$ & $0.534 \pm 0.04$ & $0.448 \pm 0.05$ & $0.390 \pm 0.05$ & $0.342 \pm 0.04$ & $0.300 \pm 0.07$ \\
E & $0.322 \pm 0.05$ & $0.582 \pm 0.07$ & $0.538 \pm 0.05$ & $0.492 \pm 0.07$ & $0.394 \pm 0.08$ & $0.352 \pm 0.05$ & $0.310 \pm 0.05$ & $0.334 \pm 0.06$ \\
\hline
\end{tabular}

A (normal group); B (negative control group); C (positive control group); D (test group with extract dose at $125 \mathrm{mg} / 20 \mathrm{~g} \mathrm{BW}$ ); (test group with extract dose at $150 \mathrm{mg} / 20 \mathrm{~g} \mathrm{BW})$.

Table 3: Feces consistency

\begin{tabular}{lllllllll}
\hline Group & \multicolumn{8}{c}{ Type of feces in period of time (days) } \\
\cline { 2 - 9 } & $\mathbf{0}$ & $\mathbf{1}$ & $\mathbf{2}$ & $\mathbf{3}$ & $\mathbf{4}$ & $\mathbf{5}$ & $\mathbf{6}$ & $\mathbf{7}$ \\
\hline A & 3 & 3 & 3 & 3 & 3 & 3 & 3 & 3 \\
B & 3 & 6 & 6 & 6 & 5 & 5 & 4 & 3 \\
C & 3 & 5 & 5 & 5 & 4 & 3 & 3 & 3 \\
D & 3 & 6 & 6 & 5 & 4 & 4 & 3 & 3 \\
E & 3 & 5 & 5 & 5 & 4 & 4 & 3 & 3 \\
\hline
\end{tabular}

A (normal group); B (negative control group); C (positive control group); D (test group with extract dose at $125 \mathrm{mg} / 20 \mathrm{~g} \mathrm{BW}$ ); $\mathrm{E}$ (test group with extract dose at $150 \mathrm{mg} / 20 \mathrm{~g} \mathrm{BW}$ ), 3 (type of feces: Like a sausage but cracks on in its surface), 4 (type of feces: Like a sausage, or snake, smooth and soft), 5 (type of feces: Soft blobs with clear cut-edges [passed easily]), 6 (fluffy pieces with ragged edges, a mushy stool)

in aggressiveness as well as the reduction of mucus-coated stool and bloody diarrhea $[14,15]$. In this study, the $S$. dysenteriae was sensitive to the ciprofloxacin; the klutuk extract was found to be bactericidal; it repaired stool consistency and prevented death in diarrheic mice. The bactericidal effect was comparable to that of the ciprofloxacin and could treat dysentery in the same time period as the klutuk extract, shown by the consistency of the stool with the ideal type on day 4 . All these antidiarrheal properties, promotes klutuk banana fruit extract in the treatment of diarrhea, especially infectious diarrheas by $S$. dysenteriae infection.

\section{CONCLUSION}

It can be concluded that the ethanol extract of klutuk banana fruits is highly potent as natural antidysentriae against $S$. dysenteriae.

\section{REFERENCES}

1. WHO. Manual for Identification and Antimicrobial Susceptibility Testing, Laboratory Processing of Fecal Specimens, Appendix x. Geneva: WHO; 2010.

2. Sur D, Ramamurthy T, Deen J, Bhattacharya SK. Shigellosis: Challenges and management issues. Indian J Med Res 2004;120:454-62.

3. Bhattacharya SK, Sur D. An evaluation of current shigellosis treatment.
Expert Opin Pharmacother 2003;4:1315-20

4. WHO. Guidelines for the Control of Shigellosis, Including Epidemics Due to Shigella dysenteriae Type 1. Geneva: WHO; 2005.

5. Ciesla WP, Guerrant RL. Infectious Diarrhea: Current Diagnosis and Treatment in Infectious Disease. New York: Lange Medical Books; 2003.

6. David AS, Christine L, Carol M, Voravit S. Antimicrobial Resistance in Shigellosis, Cholera and Campylobacteriosis. Geneva: WHO; 2001. p. 8.

7. Kusuma SAF, Soraya RM, Indah F, Resmi M. Study on the antibacterial activity of fruit extracts of Klutuk Banana (Musa balbisiana colla) against Shigella dysenteriae ATCC 13313. Asian J Pharm Clin Res 2017;10(7):220-3.

8. Kusuma SAF, Ulfa TW, Ade Z. Evaluation of antibacterial activity of Indonesian varieties sweet potato leaves extract from Cilembu against Shigella S. dysenteriae ATCC 13313. Asian J Pharm Clin Res 2017;10(2):377-80.

9. Rene K, Hortense GK, Pascal W, Jean AM, Vidal PE, Michel AF, et al. Activity of aqueous ethanol extract of Euphorbia prostrata ait on Shigella dysenteriae Type 1-induced diarrhea in rats. Indian J Pharmacol 2007;39:240-4

10. Kernbaum S. Elements of Infectious Pathology. $6^{\text {th }}$ ed. Paris: SIMEP; 1996.

11. Kumari S, Mazumder A, Bhattacharya S. Pharmacognostical and antimicrobial studies of the stem of Tabernaemontana divaricate Linn. Int J Pharm Pharm Sci 2015;7(8):101-4.

12. Ahmad B, Mohd KS, Abdurrazak M, Rao M, Zin T. Phytochemical screening, antioxidant activity of pure syringing in comparison to various solvents extracts of Musa $\times$ paradisiaca (banana) (fruit and flower) and total phenolic contents. Int J Pharm Pharm Sci 2015;7(5):242-7.

13. Di Carlo G, Autore G, Izzo AA, Maiolino P, Mascolo N, Viola P, et al. Inhibition of intestinal motility and secretion by flavonoids in mice and rats: Structure-activity relationships. J Pharm Pharmacol 1993;45(2):1054-9.

14. Balter-Seri J, Yuhas Y, Weizman A, Nofech-Mozes Y, Kaminsky E, Ashkenazi S. Role of nitric oxide in the enhancement of pentylenetetrazole-induced seizures caused by Shigella dysenteriae. Infect Immun 1999;67(12):6364-8.

15. Camuesco D, Comalada M, Rodriguez-Cabezas ME, Nieto A, Lorente MD, Concha A, et al. The intestinal anti-inflammatory effect of quercitrin is associated with an inhibition in iNOS expression. Br J Pharmacol 2004;143(90):8-18. 